\title{
Simulation analysis of turbine blade in 3D printing aquarium
}

\author{
Dyi-Cheng Chen ${ }^{1, *}$, Bo-Yan $\mathrm{Lai}^{2}$, and Fu-Yuan $\mathrm{Gao}^{3}$ \\ ${ }^{1}$ Department of Industrial Education and Technology, National Changhua University of Education, Changhua 500, Taiwan \\ ${ }^{2}$ Department of Industrial Education and Technology, National Changhua University of Education, Changhua 500, Taiwan \\ ${ }^{3}$ Department of Industrial Education and Technology, National Changhua University of Education, Changhua 500, Taiwan
}

\begin{abstract}
D printing of the flexibility is the most admirable place, no matter when or where, as long as the machine can make the abstract design of finished products or difficult to process the finished product printed out as a sample. And in the product design, through the 3D print out the entity, to more specific observation of the advantages and disadvantages of finished products, which shorten the time of many creative research and development, but also relatively reduce the defective factors. As in recent years, 3D printing technology is progressing, material adhesion, precision and parts of the degree of cooperation has increased, coupled with many parts taking into account the cost, production and other issues, and then let a lot of light load small parts or special parts choose to use 3D to print the finished product to replace. This study focuses on the plastic turbine blades that drive water in the aquarium, but the $3 \mathrm{D}$ printing is done by stacking. However, the general stress analysis software can set the material to analyze the deformation results of the force, nor the 3D to analyze the software. Therefore, this study first analyzes the deformation of turbine blade by software, and then verifies the situation of 3D printing turbine blade, and then compares the actual results of software analysis and $3 \mathrm{D}$ printing. The results can provide the future of $3 \mathrm{D}$ product consider the strength factor. The study found that the spiral blade design allows the force points to be dispersed to avoid hard focus.
\end{abstract}

\section{Introduction}

In recent years, in the literature related research, Yuen [1] proposed a modelling method based on tectonics for the characteristics of blade design iteration, such as leaf design parameters, FDM production procedures, and to explore its use of PLA plastic material strength trends. Lee et al [2] fabricated helical vanes with laminated manufacturing techniques to explore their design parameters, such as leaf length, number of leaves, leaf turns, pitch height and other conditions, for the mixing efficiency of viscous liquids, to understand the feasibility of the laminated manufacturing technology spiral blades. Because of its simulation analysis software can set the material, set the pressure to simulate the material subjected to stress and strain results, because 3D printing is stacked, and when the stress is concentrated and parallel with the material stacking direction, even if the material strength. It is easy to break from the material stack. Therefore, this study will explore the use of the water tank in the $3 \mathrm{D}$ printing turbine blade its thickness to be able to withstand and avoid fracture.

\footnotetext{
Corresponding author: dcchen@cc.ncue.edu.tw
}

\subsection{Laminated manufacturing technology (3D printing)}

Since the industry 4.0 reform, 3D printing technology has become a technology star in recent years, it is also the trend of cutting-edge manufacturing industry, due to $3 \mathrm{D}$ printing technology production process to escape the traditional framework. The idea can be achieved in short period of time. 3D printing technology will be 3D modeling parts into 2D layered slices, according to the layered slice of the material stacked to the molding position, repeated stacking action caused by the workpiece molding, different from the traditional manufacturing model to cut the workpiece material subtraction way, often cause unnecessary cost consumption. 3D printing technology using layers of stacking method of production, it can avoid unnecessary waste of material [1].

In the past, the product is in the development stage, subject to the design, open mold, trial production, testing and other processes, the time spent and human nonordinary small and medium enterprises can afford, and the use of 3D printing technology for sample design and mold manufacturing. High complexity and difficult parts can be produced in a short time, in order to facilitate the designer and the user to modify and communicate, is conducive to product development and custom production [3]. 
3D print parts can be designed through complex control of the complex geometry of the geometry, the production of integrated spiral contact, translation joints and other confidential institutions, and confirm the parts gap, but in mechanical terms can still not achieve the required strength [4]. But the surface roughness of complex geometric parts is not easy to control and is not conducive to subsequent processing, so $3 \mathrm{D}$ printing technology in the manufacturing industry is generally used for the design of prototype, sample proofing. With $3 \mathrm{D}$ scanning technology developed, through the $3 \mathrm{D}$ scan for measurement and inspection, and numerical analysis of parts, can predict the type change and improve the error, and then control the deformation data and provide design parameters [5]. The 3D printing material is from the traditional engineering plastics (ABS, PLA), gradually evolved into composite metal powder material (stainless steel, titanium alloy), so that 3D printing parts gradually toward high strength, high density and both heat-resistant wear-resistant sintered alloy steel and other aspects of development, in response to the characteristics of materials and diversification. In recent years widely used in national defense, aerospace, medical, steam locomotives, electrical and electronic industry, 3D printing technology has gradually become an important high-tech industries [6].

\subsection{Turbine blades}

Aquarium water quality control is an important work of farming, whether the quality of water or not affect the bait status of fish [7]. The general public aquarium for the adjustment of water quality will use the submersible motor, put it in the tank can create similar to the role of circulating water to control the oxygen content, temperature, turbidity, etc., and make the vibration effect of inhibition of algae in the waters of the breeding, to keep the water flow within the aquarium smooth [8]. And the most important part of the process of water circulation is the turbine blade. According to the discussion of the turbine blade force under the water, the analysis of the turbine blade strength indicates that the width of the turbine blade affects the force area of the turbine blade. The pressure is equal to the pressure multiplied by the pressure area, and the magnitude of the force applied to the turbine blade rotation is proportional to the pressure area of the turbine blade when the hydrostatic condition is constant [9].

The two-dimensional fluid pressure effects of the blade cross-sectional area of the turbine blades are related to the optimum performance achievable by the turbine blades. For the smooth rotation of the blades, the turbine blades are usually designed with existing airfoils [10]. When designing the thickness and chord length of the turbine blades, the structural strength of the turbine blades must be considered. In the preliminary stage of the turbine blade, the $3 \mathrm{D}$ computer model structure should be built quickly. Therefore, the rule of thumb is usually used according to the two- Based on the formula of fluid dynamics and logarithmic helix, the turbine blade blade size was constructed by using Inventor 2016 simulation software to establish the turbine blade geometry model and the engineering elasticity of the turbine blade. The parameters and strength parameters are as follows:

Table 1. ABS material engineering elastic parameters and strength parameters.

\begin{tabular}{l|c}
\hline Name & Parameters \\
\hline Material & ABS plastic \\
\hline Number of model grids & 10,000 \\
\hline Material density & $1.06 \mathrm{~g} / \mathrm{cm}^{\wedge} 3$ \\
\hline Yield strength & $20 \mathrm{MPa}$ \\
\hline Ultimate tensile strength & $29.6 \mathrm{MPa}$ \\
\hline Young's modulus & $2.24 \mathrm{GPa}$ \\
\hline Poisson's ratio & $0.38 \mathrm{ul}$ \\
\hline Shear modulus & $0.811594 \mathrm{GPa}$ \\
\hline
\end{tabular}

The force of the turbine blades is measured under the fixed output power of the submersible motor, and the calculated leaf load is used as the condition of the finite element analysis method to analyze the turbine blade. The required structural strength explored the $3 \mathrm{D}$ printing of the turbine blade parts and analog data differences to provide the aquarium turbine blade design reference.

\subsection{The purpose of research}

In order to make the feed flow from the internal flow of the aquarium, the feed is effectively spread out due to the flow. In this study, the turbine blades of the tank are made by $3 \mathrm{D}$ printing, and the turbine blades of different thickness are designed by the fluid mechanics calculation method, and the relationship between the stress and strain state of the force area and the blade thickness of the turbine blades in $3 \mathrm{D}$ operation is discussed.

\section{Research methods}

In this study, Inventor 2016 was used to design and draw the model, and the 3D blade turbine blades suitable for the aquarium were drawn with reference to the common turbine blade appearance. The same airfoil, stacking angle, blade number, water pressure and so on were designed parameters, only the same thickness of the turbine blades. The material was set to ABS material, and the stress and strain state of the turbine blade thickness at $2.5 \mathrm{~mm}$ were simulated. Finally, the turbine blades with thickness of $2 \mathrm{~mm}$ and $3 \mathrm{~mm}$ were fabricated by $3 \mathrm{D}$ printing technology to explore the use of $3 \mathrm{D}$ printing technology. Whether the stress strain of the turbine blade can correspond to the turbine blade of the actual injection, and understand the effect of the stress strain value on the turbine blade produced by 3D printing technology. Fig. 1 and Fig. 2 show the three dimensional model of the turbine blade at thickness $2 \mathrm{~mm}$. 


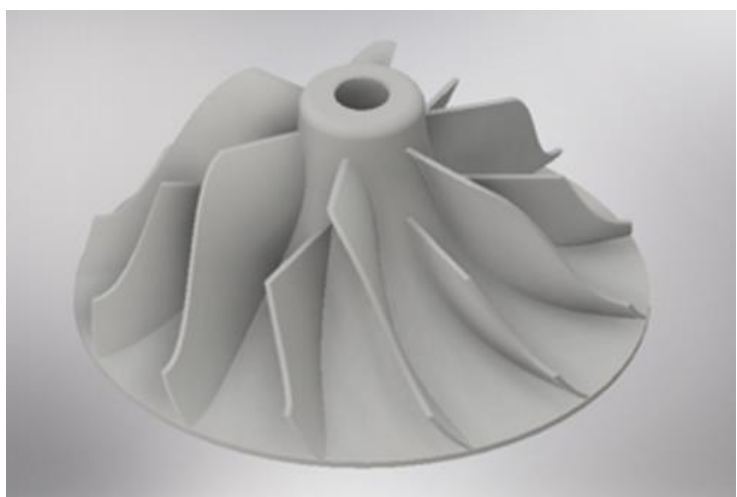

Fig.1. Turbine blade model (2mm)(up).

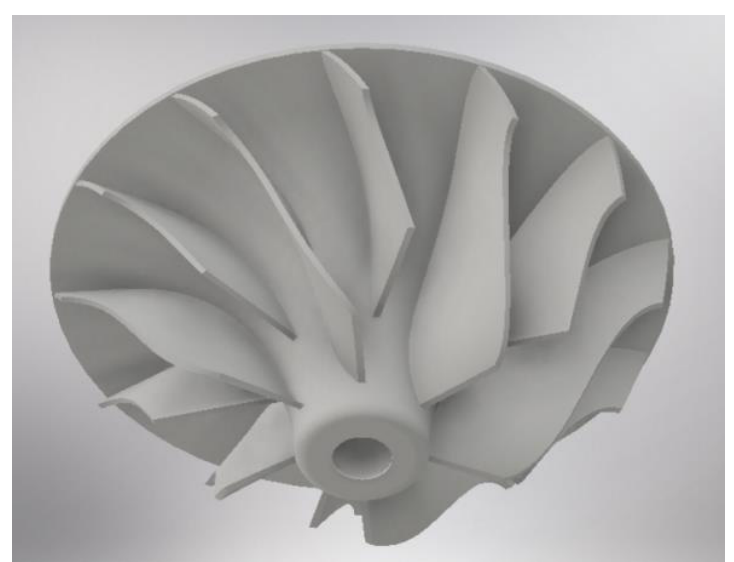

Fig. 2. Turbine blade model (2mm)(down).

In this paper, the fluid calculation based on the Renault mean (RANS) equation viscous flow theory, that the uniform flow to maintain a certain speed around the propeller is a typical three-dimensional incompressible turbulent fluid. The RANS expression for the entire computational flow field is as follows:

Continuous equation Eq. (1):

$$
\frac{\partial_{u i}}{\partial_{x i}}=0
$$

Momentum equation Eq. (2):

$$
\rho \frac{\partial\left(u_{i} u_{j}\right)}{\partial x_{j}}=\frac{\partial_{p}}{\partial x_{j}}+\frac{\partial}{\partial x_{j}}\left[\mu\left(\frac{\partial u_{i}}{\partial x_{j}}+\frac{\partial u_{j}}{\partial x_{i}}\right)\right]-\frac{\partial\left(\rho \overline{u_{i}^{\prime} u_{j}^{\prime}}\right)}{\partial x_{j}}+\rho g_{i}
$$

The fluid calculation domain is set to two parts of the fixed domain and the rotating domain to ensure the calculation in the normal state. The design of the 3D modeling geometry is set as stationary stationary objects such as water and aquarium body, and the turbine blades are set to rotation. The simulation set of turbine blade surface is defined as non-slippable wall, turbine blade placed in the aquarium depth and blade size according to the size of the aquarium. The simulation set the turbine blade thickness of $2.5 \mathrm{~mm}$, the simulation set material for the ABS Material.

\section{Results and discussion}

\subsection{Effective stress and strain analysis of turbine blade - force $5 \mathrm{~N}$}

Fig. 3 shows effective stress of turbine blades on $5 \mathrm{~N}$, and Fig. 4 shows effective strain of turbine blades on $5 \mathrm{~N}$. It is understood from the figure that the effective strain is evenly distributed at the leaf edge of the turbine blade with a minimum effective strain of 0.005 and a maximum effective strain of 5.97. The minimum effective stress is $0.0001 \mathrm{MPa}$ and the maximum effective stress is $0.1436 \mathrm{MPa}$.

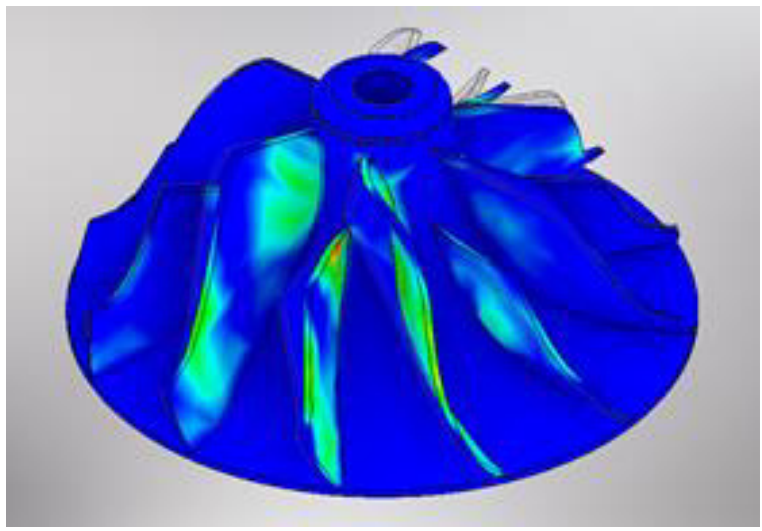

Fig. 3. Effective stress of turbine blades on $5 \mathrm{~N}$.

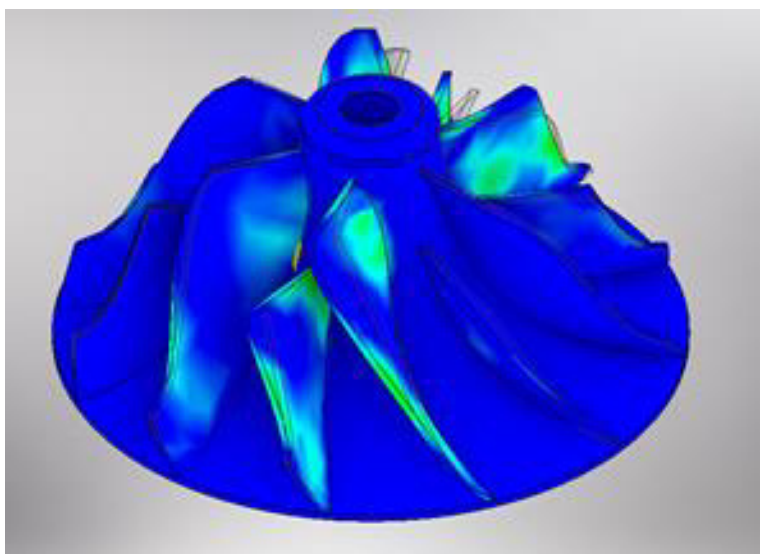

Fig. 4. Effective strain of turbine blades on $5 \mathrm{~N}$.

\subsection{Effective stress and strain analysis of turbine blade - force $10 \mathrm{~N}$}

Fig. 5 shows efective stress of turbine blades on $10 \mathrm{~N}$, and Fig. 6 shows effective strain of turbine blades on $10 \mathrm{~N}$. It is understood from the figure that the effective strain is evenly distributed at the leaf edge of the turbine blade with a minimum effective strain of 0.006 and a maximum effective strain of 7.17 . The minimum effective stress is $0.0001 \mathrm{MPa}$ and the maximum effective stress is $0.1725 \mathrm{MPa}$. 


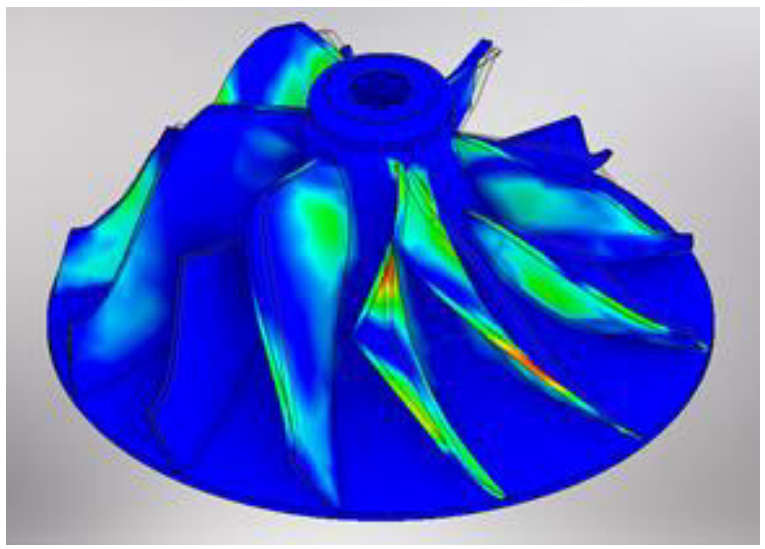

Fig. 5. Efective stress of turbine blades on $10 \mathrm{~N}$.

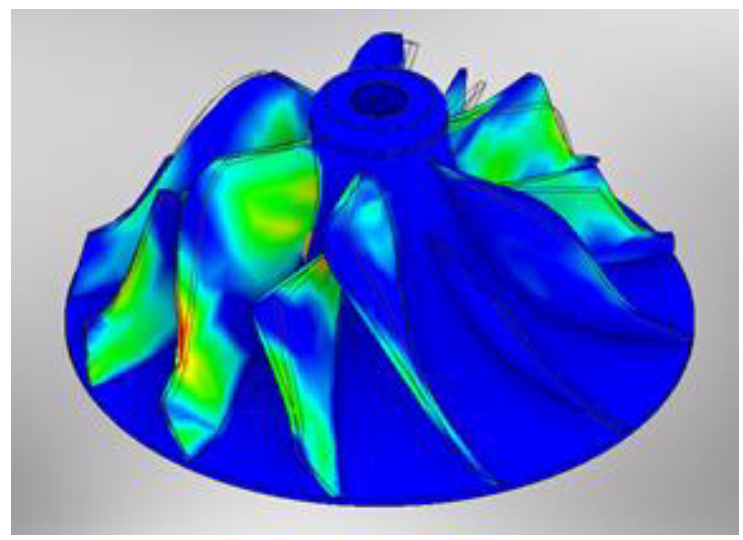

Fig. 6. Effective strain of turbine blades on $10 \mathrm{~N}$.

\subsection{Effective stress and strain analysis of turbine blades - force $15 \mathrm{~N}$}

Fig. 7 shows efective stress of turbine blades on $15 \mathrm{~N}$, and Fig. 8 shows effective strain of turbine blades on $15 \mathrm{~N}$. It is understood from the figure that the effective strain is evenly distributed at the leaf edge of the turbine blade with a minimum effective strain of 0.013 and a maximum effective strain of 10.66. Its effective stress quality minimum $0.0003 \mathrm{MPa}$, the maximum effective stress value of $0.256 \mathrm{MPa}$.

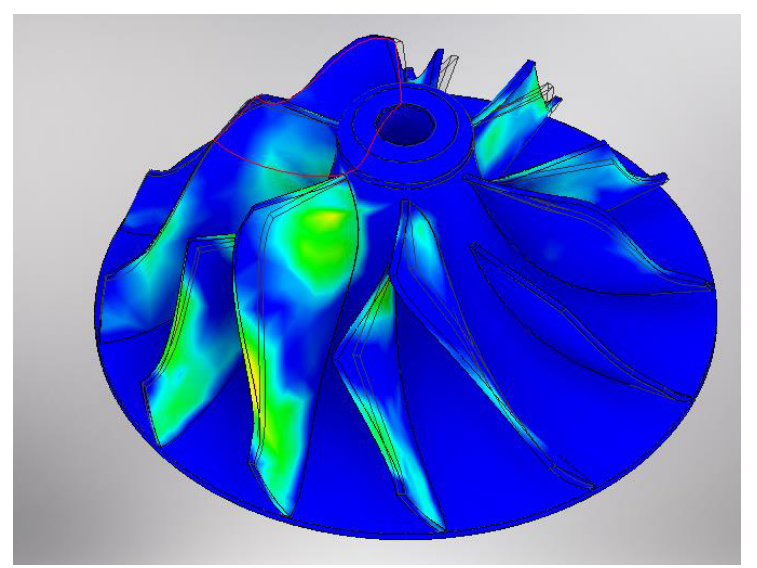

Fig.7 Effective stress of turbine blades on $15 \mathrm{~N}$.

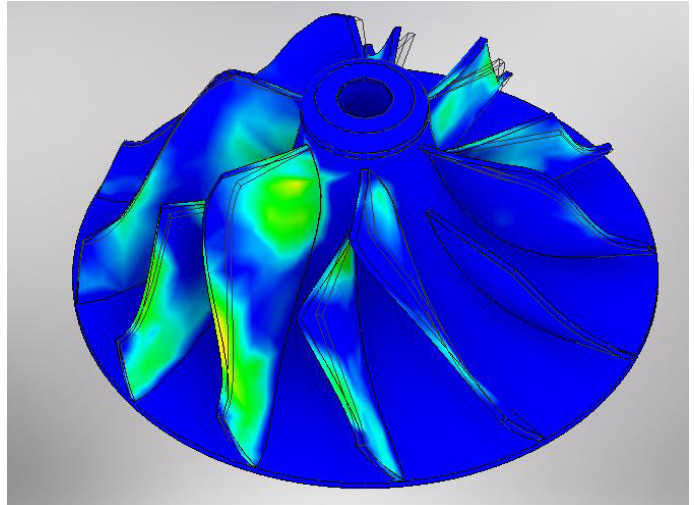

Fig.8. Effective strain of turbine blades on $15 \mathrm{~N}$

\subsection{Effective stress and strain analysis of turbine blade - force $20 \mathrm{~N}$.}

Fig. 9 shows efective stress of turbine blades on $20 \mathrm{~N}$, and Fig. 10 shows effective strain of turbine blades on $20 \mathrm{~N}$. It is understood from the figure that the effective strain is evenly distributed at the leaf edge of the turbine blade with a minimum effective strain of 0.096 and a maximum effective strain of 11.52. The minimum effective stress is $0.0004 \mathrm{MPa}$, the maximum effective stress is $0.278 \mathrm{MPa}$.

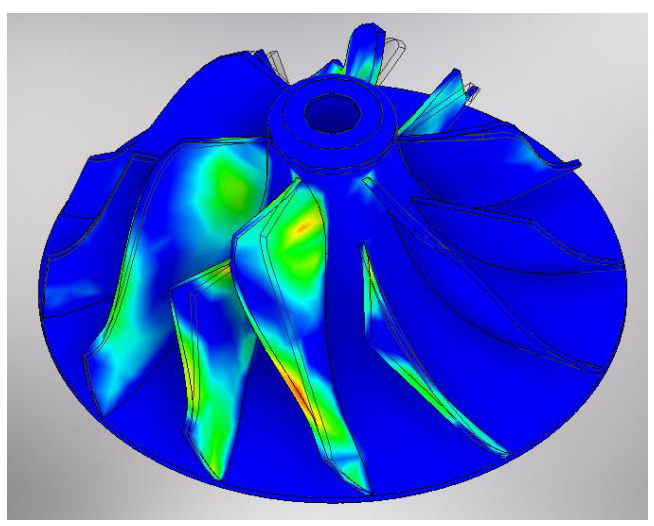

Fig. 9. Effective stress of turbine blades on $20 \mathrm{~N}$.

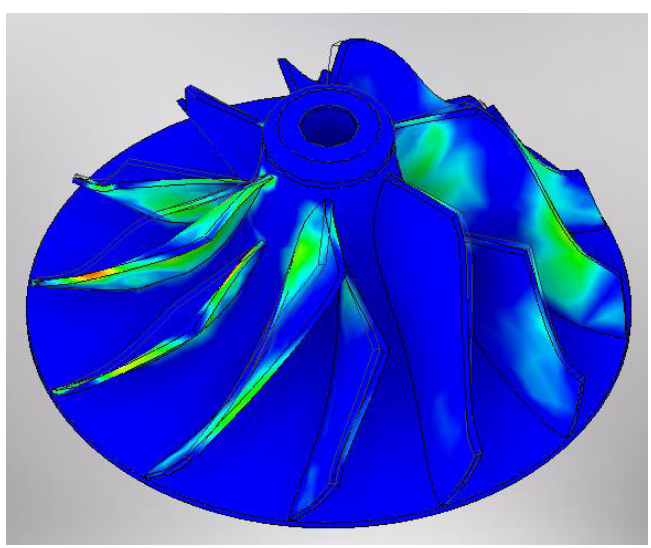

Fig.10. Effective strain of turbine blades on $20 \mathrm{~N}$. 


\section{Conclusions}

In this study, the model of the turbine blade is actually made by $3 \mathrm{D}$ printing technology. It is found that the turbine blade with different blade thickness can be consistent with the simulation. Through the above analysis, it is found that the turbine blade with the thickness of $2 \mathrm{~mm}$ is in the actual operation. After 10 hours, there was a serious damage to the tube wall. The turbine blades with a blade thickness of $3 \mathrm{~mm}$ were able to operate normally after 24 hours of operation. It indicated that the stress and strain energy of the turbine blades produced by $3 \mathrm{D}$ printing technology could be simulated with the simulated injection turbine blades correspond to their effective stress and effective strain. The turbine blades made by 3D printing technology produce breakage of material under the condition of blade thickness of $2 \mathrm{~mm}$. The turbine blades made by $3 \mathrm{D}$ printing technology can be used in the case of blade thickness of $3 \mathrm{~mm}$ consistent with the simulation results, and in the actual operation of the process has a good strength.

\section{References}

1. P.K. Yuen, Embedding objects during 3D printing to add new functionalities. Biomicro-fluidics,10(4), $1-10(2016)$

2. W. Lee, S. Jeon, D. Kim, 3d-printed micromixer with helical blades for highviscosity fluids. Department of Chemical Engineering, [online] Available:http://www.rsc.org/images/LOC/2015/PD Fs/Papers/1253 T.320e. (2015)

3. Y.S. Huang, Process and application of metal powder. Science Development Monthly, 523,10-14 (2016)

4. Iñigo Flores Ituarte, Eric Coatanea, Mika Salmi, Jukka Tuomi, Jouni Partanen, Additive manufacturing in production: a study case applying technical requirements, Physics Procedia, 78, 357366 (2015)

5. T. Seno, Y. Ohtake, Y. Kikuchi, N. Saito, H. Suzuki, Y. Nagai, 3D scanning based mold correction for planar and cylindrical parts in aluminum die casting, Journal of Computational Design and Engineering, 2(2), 96-104 (2015)

6. W. Lin, W. Liu, X. Liang, Development and prospecting application of metal powder process technology and equipment for curing, Taichung City: Metal Industry Research and Development Center, (2014)

7. M. Li, M. Hong, J. Chen, Q. You, X. Huang, Automatic feeding and water quality analysis of indigenous type indoor circulation aquaculture system, Journal of Agriculture and Forestry, 49 (4), 85-98 (2000)

8. G. Peng, How to create a viable ecological pool. Conservation of Nature, 35 (9), 6-10 (2001)

9. Y.R. Jiang, Yi Ru, Design and analysis of small wind turbine blade, Wind Power Monthly, 2(2006)
From:http://www.twtia.org.tw/upload/111/20066617 13205148

10. J. Tangler, J. David, Kocurek, Wind turbine poststall airfoil performance characteristics guidelines for blade-element momentum methods, NREL/CP500-36900 Oct. 2004 